\title{
Atypical Hemolytic Uremic Syndrome in the Setting of Acute Clostridium difficile Colitis
}

\author{
Anshu Wadehra ${ }^{1}$, Samer Alkassis ${ }^{1}$ \\ 1. Internal Medicine, Wayne State University/Detroit Medical Center, Detroit, USA
}

Corresponding author: Anshu Wadehra, awadehra@med.wayne.edu

\begin{abstract}
Hemolytic uremic syndrome (HUS) is characterized by microangiopathic hemolytic anemia, thrombocytopenia, and acute renal failure. HUS can be secondary to multiple etiologies such as infections, medications, and immune processes. A rare, yet significant, etiology of HUS includes acute Clostridium difficile colitis. Here, we present a case of atypical HUS secondary to acute C. difficile colitis, successfully treated with hemodialysis and systemic corticosteroids. It is imperative that clinicians are cognizant of $C$. difficile-associated HUS given the overall rising incidence of acute $C$. difficile infections.
\end{abstract}

Review began 02/02/2021 Review ended 02/07/2021 Published 02/09/2021

\section{(๑) Copyright 2021}

Wadehra et al. This is an open access article distributed under the terms of the Creative Commons Attribution License CC-BY 4.0., which permits unrestricted use, distribution, and reproduction in any medium, provided the original author and source are credited.
Categories: Gastroenterology, Infectious Disease, Hematology

Keywords: hus, clostridium difficile, atypical hemolytic uremic syndrome

\section{Introduction}

Hemolytic uremic syndrome (HUS), as defined by the triad of microangiopathic hemolytic anemia, thrombocytopenia, and acute kidney injury, has been shown to be the result of many bacterial infections [1]. Additionally, HUS can be secondary to viral infections, medications, and immune processes [2-4]. The most commonly reported causative bacteria include Escherichia coli O157:H7, Shigella dysenteriae, Salmonella typhi, and Streptococcus pneumoniae [3]. Clostridium difficile has been rarely reported as a causative microbe in the development of HUS in the adult population [3]. Treatment of this entity typically involves supportive care; however, hemodialysis and blood transfusions may be required [5]. We present a case of an adult patient who was diagnosed with HUS secondary to $C$. difficile colitis.

\section{Case Presentation}

The patient was a 65 -year-old male with significant medical history of immunoglobulin G multiple myeloma and hypertension, who presented to the hospital with three days of generalized fatigue and multiple daily episodes of non-bloody, watery diarrhea. He had mild diffuse abdominal tenderness on physical examination. On admission, laboratory workup was significant for acute renal failure, with serum creatinine of $7.77 \mathrm{mg} / \mathrm{dL}$ and blood urea nitrogen of $66 \mathrm{mg} / \mathrm{dL}$. His serum creatinine measured five days prior to admission was $1.00 \mathrm{mg} / \mathrm{dL}$. The patient was also noted to be anuric.

Further laboratory studies showed lactate dehydrogenase being significantly elevated to 3,835 U/L. Haptoglobin was low and total bilirubin was $1.12 \mathrm{mg} / \mathrm{dL}$, with fractionation revealing it to be primarily unconjugated. Alanine aminotransferase and aspartate aminotransferase were elevated to $70 \mathrm{IU} / \mathrm{L}$ and 220 IU/L, respectively. Stool studies revealed a positive $C$. difficile polymerase chain reaction. Shiga toxin was negative. Stool culture was negative for Salmonella and Shigella as well.

Complete blood count revealed severe thrombocytopenia at $4,000 / \mathrm{mm}^{3}$. Platelet count was $274,000 / \mathrm{mm}^{3}$ five days prior to admission. Hemoglobin was reduced to $9.3 \mathrm{~g} / \mathrm{dL}$ from his previous baseline of $12.0 \mathrm{~g} / \mathrm{dL}$, without any overt signs of bleeding. Mean corpuscular volume was $88.8 \mathrm{fL}$ and INR was 1.00. ADAMTS13 activity was within normal limits at $93 \%$. Coombs test was negative as well. Peripheral blood smear was reviewed and showed schistocytes (Figure 1). Based on these pertinent findings, a diagnosis of HUS was established. 


\section{Cureus}

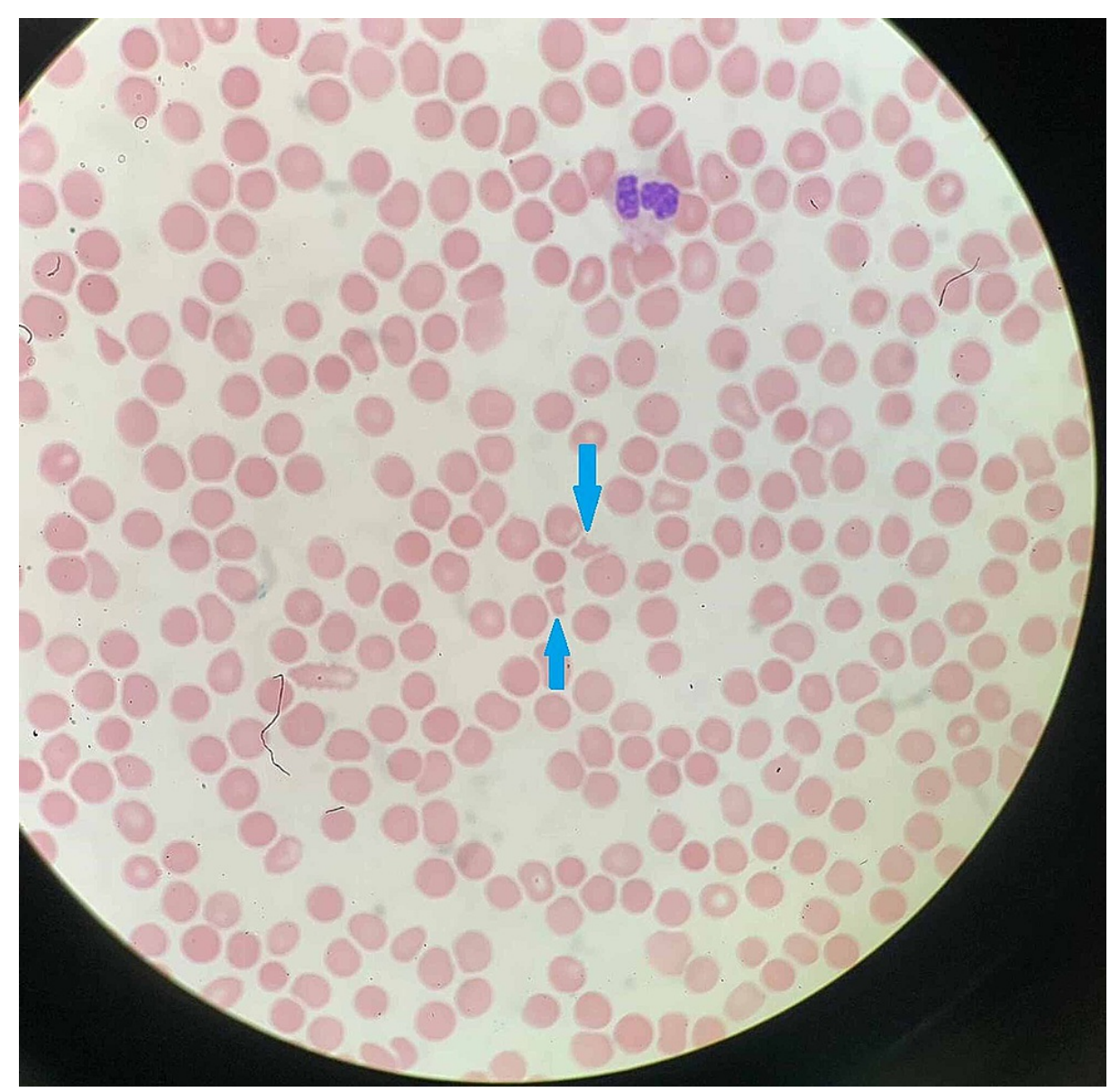

FIGURE 1: Peripheral blood smear revealing schistocytes (blue arrows).

During his hospital course, platelet count improved to $51,000 / \mathrm{mm}^{3}$ with supportive care, which later dropped to $19,000 / \mathrm{mm}^{3}$. Given his further drop in platelets, the decision was made to start the patient on high-dose intravenous (IV) methylprednisolone. The patient also required multiple red blood cell transfusions throughout his hospitalization to maintain his hemoglobin above a value of $7 \mathrm{~g} / \mathrm{dL}$.

The patient was treated for $C$. difficile infection with oral vancomycin. His renal function continued to decline during his hospital course, eventually requiring hemodialysis. He received five days of high dose IV methylprednisolone with resultant improvement of his platelet count to $86,000 / \mathrm{mm}^{3}$ on the day of discharge. Overall, his symptoms improved, and the patient was discharged with a prolonged steroid taper and continued outpatient hemodialysis.

\section{Discussion}

HUS is a form of thrombotic microangiopathy characterized by microangiopathic hemolytic anemia, thrombocytopenia, and acute renal failure [6]. It was formerly classified into typical HUS, which is caused by Shiga toxin-producing $E$. coli and considered the most common type in children, and atypical HUS, or nonShiga toxin HUS, which accounts for most of the adult cases [7]. The new classification was developed based on the pathophysiology and precipitating factors [8]; hereditary causes include complement gene mutations and cobalamin C deficiency. Acquired causes involve autoantibodies to complement factors, drug-induced, and infection.

Many infections have been associated with HUS including human immunodeficiency virus and S. pneumoniae $[9,10]$. C. difficile has been recognized as a rare trigger for HUS [3,11-13]. In contrast to E-coli-associated HUS, adults with $C$. difficile-associated HUS may have better prognosis than children [3]. The pathophysiology of $C$. difficile-associated HUS is not well understood; it was speculated that binding of cytotoxin A and B to specific receptors on colonic cell membranes induces apoptosis leading to mucosal breach and cytotoxin access into circulation, which may directly damage the renal microvasculature [3].

The diagnosis of HUS is clinically based on the presence of the classical triad, which is established by laboratory workup that includes a complete blood count with peripheral blood smear, renal functions 
studies, and urinalysis. Microangiopathic hemolytic anemia is defined by a hemoglobin level less than 10 $\mathrm{g} / \mathrm{dL}$ with a negative Coombs test and a peripheral blood smear demonstrating schistocytes (up to $10 \%$ of red cells) and helmet cells [1]. Thrombocytopenia is characterized by a platelet count below $140,000 / \mathrm{mm}^{3}$. The degree of thrombocytopenia is unrelated to the severity of renal dysfunction. The severity of acute kidney injury ranges from hematuria and proteinuria to severe renal failure and oliguria.

The cornerstone management in HUS is supportive therapy, including red blood cell and platelet transfusion when clinically indicated, fluid and electrolyte management to maintain adequate intravascular volume and correct electrolyte abnormalities, and discontinuation of nephrotoxic medications [5]. Initiation of dialysis is indicated in patients with symptomatic uremia, severe fluid overload, or electrolyte abnormality that is refractory to medical therapy. Different conventional treatments have been used in C. difficile-associated HUS, including antibiotics, corticosteroids, and plasmapheresis with convenient response [14]. Eculizumab, a terminal complement inhibitor, has been shown to be effective and safe in atypical HUS, particularly in regards to long-term renal function and thrombotic microangiopathic events, based on a recent large prospective, observational, multicenter study [15]. Our patient completed 14-day course of oral vancomycin. In addition, he also received high-dose corticosteroids and was discharged on a tapering dose of prednisone.

\section{Conclusions}

C. difficile infection may cause renal failure due to thrombotic microangiopathy which should be considered in the differential diagnosis of diarrhea-associated HUS. Treatment of this entity includes primarily supportive care; however, if inadequate response is observed, systemic corticosteroids may prove to be beneficial. With the rising incidence of pseudomembranous colitis, clinicians should be aware of the unusual manifestations of this common illness.

\section{Additional Information \\ Disclosures}

Human subjects: Consent was obtained or waived by all participants in this study. Conflicts of interest: In compliance with the ICMJE uniform disclosure form, all authors declare the following: Payment/services info: All authors have declared that no financial support was received from any organization for the submitted work. Financial relationships: All authors have declared that they have no financial relationships at present or within the previous three years with any organizations that might have an interest in the submitted work. Other relationships: All authors have declared that there are no other relationships or activities that could appear to have influenced the submitted work.

\section{References}

1. Noris M, Remuzzi G: Hemolytic uremic syndrome. J Am Soc Nephrol. 2005, 16:1035-50. 10.1681/ASN.2004100861

2. Caltik A, Akyüz SG, Erdogan O, Demircin G: Hemolytic uremic syndrome triggered with a new pandemic virus: influenza A (H1N1). Pediatr Nephrol. 2011, 26:147-8. 10.1007/s00467-010-1649-0

3. Keshtkar-Jahromi M, Mohebtash M: Hemolytic uremic syndrome and Clostridium difficile colitis. J Community Hosp Intern Med Perspect. 2012, 2:19064. 10.3402/jchimp.v2i3.19064

4. Tarr PI, Gordon CA, Chandler WL: Shiga-toxin-producing Escherichia coli and haemolytic uraemic syndrome. Lancet. 2005, 365:1073-86. 10.1016/S0140-6736(05)71144-2

5. Bitzan M: Treatment options for HUS secondary to Escherichia coli O157:H7 . Kidney Int Suppl. 2009, 112:62-6. 10.1038/ki.2008.624

6. Mele C, Remuzzi G, Noris M: Hemolytic uremic syndrome. Semin Immunopathol. 2014, 36:399-420. 10.1007/s00281-014-0416-X

7. Khurshid Q, Mahmoud A, Shahid M, Mohamed A, Shahbaz A: Atypical hemolytic uremic syndrome associated with Clostridium difficile infection. Cureus. 2020, 12:9005. 10.7759/cureus.9005

8. Aigner C, Schmidt A, Gaggl M, Sunder-Plassmann G: An updated classification of thrombotic microangiopathies and treatment of complement gene variant-mediated thrombotic microangiopathy. Clin Kidney J. 2019, 12:333-7. 10.1093/ckj/sfz040

9. Waters AM, Kerecuk L, Luk D, et al.: Hemolytic uremic syndrome associated with invasive pneumococcal disease: the United kingdom experience. J Pediatr. 2007, 151:140-4. 10.1016/j.jpeds.2007.03.055

10. Turner ME, Kher K, Rakusan T, D'Angelo L, Kapur S, Selby D, Ray PE: A typical hemolytic uremic syndrome in human immunodeficiency virus-1-infected children. Pediatr Nephrol. 1997, 11:161-3. 10.1007/s004670050249

11. Mogyorosi A, Carley MD: Hemolytic-uremic syndrome associated with pseudomembranous colitis caused by Clostridium difficile. Nephron. 1997, 76:491. 10.1159/000190237

12. Mbonu CC, Davison DL, El-Jazzar KM, Simon GL: Clostridium difficile colitis associated with hemolyticuremic syndrome. Am J Kidney Dis. 2003, 41:14. 10.1016/s0272-6386(03)00210-5

13. Alvarado AS, Brodsky SV, Nadasdy T, Singh N: Hemolytic uremic syndrome associated with Clostridium difficile infection. Clin Nephrol. 2014, 81:302-6. 10.5414/CN107691

14. Inglis JM, Barbara JA, Juneja R, Milton C, Passaris G, Li JYZ: Atypical haemolytic uraemic syndrome associated with Clostridium difficile infection successfully treated with eculizumab. Case Rep Nephrol. 2018, 2018:1759138. 10.1155/2018/1759138

15. Menne J, Delmas Y, Fakhouri F, et al.: Outcomes in patients with atypical hemolytic uremic syndrome treated with eculizumab in a long-term observational study. BMC Nephrol. 2019, 20:125. 10.1186/s12882- 


\section{Cureus}

019-1314-1 